\title{
Clinical Evaluation of 762 Single-Tooth, Locking-Taper Implants: A Prospective Study with 1- to 12-Years of Follow-Up \\ Mangano $\mathrm{FG}^{*}$, Colombo $\mathrm{M}^{2}$ and Mangano $\mathrm{C}^{3}$
}

${ }^{1}$ Post-Graduate Student and Lecturer, Department of Surgical and Morphological Science, Dental School, University of Insubria, Via Giuseppe Piatti 10, 21100, Varese, Italy

${ }^{2}$ Post-Graduate Student, Department of Surgical and Morphological Science, Dental School, University of Insubria, Via Giuseppe Piatti 10, 21100, Varese, Italy

${ }^{3}$ Professor, Department of Medical, Oral and Biotechnological Sciences, Dental School, University G. d' Annunzio, Via dei Vestini 37, 66100 Chieti, Italy

${ }^{*}$ Corresponding author: Mangano FG, Post-Graduate Student and Lecturer, Department of Surgical and Morphological Science, Dental School, University of Insubria, Via Giuseppe Piatti 10, 21100, Varese, Italy, Fax: +39- 0344-530251, Tel: +39-0344-85524, E-mail: francescoguidomangano@gmail.com

Citation: Mangano FG, Colombo M, Mangano C (2016) Clinical Evaluation of 762 single-Tooth, LockingTaper Implants: A Prospective Study with 1- to 12-Years of Follow-Up. J Dent Oral Care Med 2(2): 201. doi: $10.15744 / 2454-3276.2 .201$

\section{Received Date: December 22, 2015 Accepted Date: May 09, 2016 Published Date: May 10, 2016}

\begin{abstract}
Background: The aim of this study was to evaluate the survival rate, complications and marginal bone loss of single-tooth lockingtaper implants.

Materials and Methods: Between January 2002-December 2013, all patients referred to two dental clinics for treatment with single implants were enrolled in this study. Locking- taper implants (Leone Implants ${ }^{\circledR}$, Florence, Italy) were placed with a two-stage technique. The outcome measurements were implant survival, biological/prosthetic complications, marginal bone loss (MBL). The surviving implant-supported restorations were defined as "complication-free" in the absence of any complication. The cumulative implant survival rate and "complication-free" survival of restorations were identified using the Kaplan- Meier method. Log-rank, Breslow and Tarone-Ware analyses were used to evaluate correlations between the study variables.

Results: 762 implants were placed in 654 patients (324 males, 330 females; aged between 21-80 years, mean age $52.7 \pm 14.4$ years). Eighteen implants (11 maxilla, 7 mandible) failed, giving an overall cumulative implant survival rate of $96.9 \%$ (patient-based) and $97.3 \%$ (implant-based) at 12 -year follow-up. Among the surviving 744 implants, 45 biological complications (6.0\%) and 26 prosthetic complications (3.4\%) were reported, giving a 12-year cumulative "complication-free" survival of restorations of 72.7\%. A mean MBL of $0.34( \pm 0.27 \mathrm{~mm}), 0.46( \pm 0.29 \mathrm{~mm})$ and $0.83( \pm 0.41 \mathrm{~mm})$ was observed, respectively at the 1-, 6- and 12-year follow-up examinations. Conclusions: Locking-taper implants represent a good treatment option for the rehabilitation of single-tooth gaps in the long-term, with high survival rates and low incidence of complications.
\end{abstract}

Keywords: Single-tooth implants; Locking-taper implants; Survival; Complications; Marginal bone loss

\section{Introduction}

Nowadays, dental implants represent the state-of-the-art treatment for replacing single missing teeth, as demonstrated by several long-term follow-up studies, with satisfactory high survival rates [1-4]. However, biological and prosthetic complications still affect single crowns (SCs) supported by dental implants [2,5-10]. Biological complications include complications that affects only soft tissues (such as pain and swelling after surgery, or peri-implant mucositis) and complications that affect both soft and hard tissues (such as peri-implantitis) $[5,6,10]$. Prosthetic complications include mechanical complications (i.e. complications that affect prefabricated implant components, such as screw or abutment loosening, screw or abutment fracture) and technical complications (i.e. complications that affect superstructures, such as fracture/chipping of veneering materials and the need for recementation) [9-13].

In general, prosthetic complications, such as abutment screw loosening, loss of retention and fracture of the veneering material are the most frequent complications encountered [2,6-10,13-17]. Clinical studies on single-unit restorations have reported abutment screw loosening percentages between $5 \%$ and $48 \%$ [2,6-10,13-17]. These complications seem to affect mostly the posterior chewing, where the mechanical loads are higher [9,10,15-17] . 
Although abutment screw loosening may not lead to implant failure, it represents a problem, because it takes time to remove the crown and screw it again; moreover, where frequent, screw loosening may adversely affect the patient's satisfaction with the implant treatment $[5,6,12,13]$. Now-a-days, in fact, patients have high functional and esthetic expectations in relation to dental therapies [5]. Since patient satisfaction is a key, it is therefore very important to minimize the incidence of complications [5]. Screw loosening has been generally related to the type of implant/abutment connection used. Screw type connections, such as butt-joint indexed external or internal connections, are still the most commonly used in the market [18-20]. These connections are mainly stabilized by the axial preload of the abutment screw: as a consequence, optimum preload is critical for joint stability [18-20]. The stability of butt-joint connections can be challenged by occlusal loads: when these exceed the resistance of the torqued implantabutment system, screw may loose or break $[19,20]$. In addition, screw loosening may occur as a result of fatigue, when lower masticatory forces, applied repeatedly, surpass the failure threshold of the assembly $[19,20]$.

A valid alternative to butt-joint connections can be the introduction of conical connections [20]. A recent systematic review of the literature have found a low incidence of prosthetic complications when implants with internal conical connections were used [21]. Locking-taper connection implants are another possible alternative [22,23].

Locking-taper connection implants have no screw, and the abutment is retained only by means of friction force. This connection works under the principle of "cold welding": it relies on the large contact pressure and frictional resistance between the surfaces of the implant and the abutment [22,23]. Locking-taper implants have demonstrated mechanical advantages over screw-type, buttjoint connections: they can resist eccentric loads and bending moments, ensuring a remarkable stability, as demonstrated in several studies [22,23]. Different clinical studies have found a low incidence of prosthetic complications when locking-taper implants were used [24-31]. Only a few studies, however, have reported on the incidence of biological and prosthetic complications encountered with locking-taper implants in the long-term [28-31], and little is known about the long-term clinical outcomes of SCs supported by locking-taper implants [29]. An interesting way to describe the susceptibility to complications, whether biological or prosthetic, is to report the "complication-free" survival rate of restorations $[28,31,32]$. This index indicates a restoration that is not affected by any complications, neither biological nor prosthetic [28,31,32]. The use of this index allows to objectively evaluate if a restoration is successful in the long term or not, because affected by biological and/or prosthetic complications [31,32]. Hence, the aim of this prospective long-term follow-up clinical study was to assess the implant survival and "complication-free" survival rate of singletooth restorations; in addition, the marginal bone loss around these implants was evaluated.

\section{Materials and Methods}

\section{Patient selection}

Over a 12-year period (January 2002- December 2013) all patients referred to two private dental clinics for treatment with oral implants were considered for inclusion in the present study. Inclusion criteria were as follows: (1) age > 18 years, (2) good systemic and oral health; (3) installation of single implants; (4) at least 4 months of healing after tooth extraction; (5) dentition in the opposing jaw to have occlusal contacts. The following exclusion criteria were applied: (1) systemic diseases that would not allow an intervention; (2) uncontrolled diabetes mellitus; (3) immune-compromised status; (4) treatment with bisphosphonates; (5) active periodontal infections; (6) insufficient bone volume to place implants of at least $3.3 \mathrm{~mm}$ diameter and $8.0 \mathrm{~mm}$ length; (7) drug abuse; (8) psychologic disorders. Patients were informed that smoking is associated with an increased risk of implant failure [32]. All patients were clearly informed about the proposed treatment protocol including its possible risks of complications; after that, a written informed consent form was obtained. All patients agreed to participate in a post-operative control program. The study was conducted in accordance with the principles outlined in the Declaration of Helsinki on clinical research involving human subjects, 1975, as revised in 2000, and approved by the local Ethical Committee at the Hospital of Varese, Italy (protocol 0034086, number 826).

\section{Pre-operative assessment}

All patients underwent a complete clinical and radiographic examination. Alginate impressions (Hydrogum5 $5^{\circledR}, \mathrm{Zhermack}, \mathrm{Badia}$ Polesine, Italy) were taken and stone casts were used for a preliminary diagnostic wax-up. In addition, peri-apical radiographs were taken, with the aid of a Rinn alignment system (Rinn ${ }^{\oplus}$, Dentsply, Elgin, IL, USA), in order to assess the available bone height for implant placement. Computerized tomography (CT) and cone beam computed tomography (CBCT) were used as final investigation, where needed. CT/CBCT datasets were transferred to specific 3D reconstruction software (Mimics ${ }^{\oplus}, \mathrm{Materialise}$, Leuven, Belgium) where it was possible to correctly assess the width of each implant site and the thickness and the density of the cortical plates and the cancellous bone, as well as the ridge angulations.

\section{Surgical and prosthetic procedures}

Locking-taper implants (Leone Implants ${ }^{\oplus}$, Florence, Italy) were used. These implants feature a tapered-interference-fit combined with an internal hexagon (Figure 1). All surgical and restorative treatments were performed by the same experienced oral surgeon (C.M.). Local anaesthesia was obtained by infiltrating articaine 4\% containing 1: 100,000 adrenaline (Ubistesin ${ }^{\oplus}$; 3 M Espe, St Paul, MN, USA). A midcrestal incision was made at the sites of implant placement. The mesial and the distal aspects of the crestal incision 
were connected to two vertical releasing incisions. Full-thickness flaps were reflected exposing the alveolar ridge, and preparation of implant sites was carried out with spiral drills of increasing diameter $(2.8 \mathrm{~mm}$ to place an implant with $3.3 \mathrm{~mm}$ diameter; 2.8 and $3.5 \mathrm{~mm}$ to place an implant with $4.1 \mathrm{~mm}$ diameter; an additional $4.2 \mathrm{~mm}$ drill was used to prepare the site for $4.8 \mathrm{~mm}$ diameter implants), under constant irrigation. The implant neck was positioned slightly below the bone crest. Implants were left submerged for 4 months, then provisional acrylic resin restorations were provided. The temporary restorations remained in situ for 3 months, after which definitive, ceramo-metallic restorations were provided. All restorations were cemented with zinc oxide-eugenol cement (Temp-Bond ${ }^{\oplus}$, Kerr, Orange, CA, USA). Occlusion was thoroughly checked, using articulator papers (Bausch articulating paper ${ }^{\oplus}$; Bausch Inc, Nashua, NH, USA).

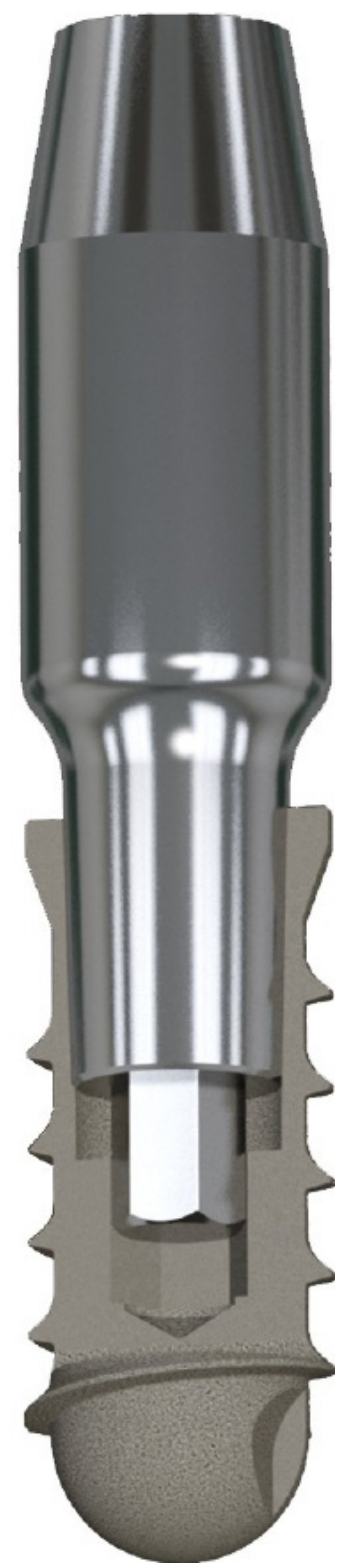

Figure 1: Drawing of the implant-abutment connection used in this study (Leone Implant System ${ }^{\oplus}$, Florence, Italy). This implant system presents a locking taper combined with an internal hexagon. The taper presents an angle of $1.5^{\circ}$

\section{Clinical follow-up examination}

Each subject was enrolled in an annual recall program. The primary outcomes variables were as follows:

Implant failure: Implant losses were all categorised as failures. The conditions for which implant removal could be indicated included: (1) failure to osseointegrate with implant mobility; (2) persistent/recurrent peri-implant infections with pain, suppuration/ exudation, severe radiographic bone loss; (3) progressive, severe marginal bone loss (MBL) in absence of peri-implant infection; (4) implant body fracture. The failures were classified into two types: early failures (before the abutment connection) and late failures (after the abutment connection). 
Complications: Complications were divided into biological and prosthetic complications. Biological complications included: (1) pain and/or swelling after surgery; (2) peri-implant mucositis (soft tissue inflammation with pain and/or swelling, without any sign of radiographic bone loss); (3) peri-implantitis with fistula formation, pain, suppuration/exudation, radiographic bone loss (the threshold to define peri-implantitis was set at a probing pocket depth $>6 \mathrm{~mm}$ with bleeding on probing, suppuration/ exudation and a MBL > $2.5 \mathrm{~mm}$ ) [34]; (4) MBL > $1.5 \mathrm{~mm}$ after the first year of function, or exceeding $0.2 \mathrm{~mm}$ for each following year [35], without clinical signs of peri-implant infection. Prosthetic complications included: (1) abutment loosening; (2) abutment fracture; (3) decementation; (4) ceramic/veneer chipping or fractures. The surviving implant-supported restorations were defined as "complication-free" in the absence of any biological or prosthetic complication, during their entire follow-up period [31,32].

Peri-implant marginal bone loss (MBL): Periapical radiographs were taken for each implant, with the aid of a Rinn alignment system (Rinn ${ }^{\oplus}$, Dentsply, Elgin, IL, USA). Customized positioners, composed of polyvinyl siloxane, were used for precise repositioning and stabilization of the radiographic template. Radiographs were taken after implant placement, at the placement of definitive restoration, and at 1-, 6- and 12-year follow-up examinations, respectively. Bone levels were measured at the mesial and distal site of each implant, at baseline and recall evaluations, using an ocular grid (magnification: $4.5 \times$ ). The most coronal bone to implant contact and the margin of the implant neck were the reference points used for measurements. To account for variability, the implant dimension (length) was measured on the radiograph and then compared with the actual fixture dimensions: ratios were calculated to adjust for distortion. After that, crestal bone changes were measured as modifications in the peri-implant marginal bone level at different time periods, on the mesial and distal implant side; then, the average from the mesial and distal calculations was used as the final MBL value, as previously described [35]. All measures were taken by the same independent calibrated observer, who was not part of the treating team.

\section{Statistical analysis}

Databases were created with a computerized worksheet (Excel $2003^{\circ}$, Microsoft Corporation, Redmond, WA, USA) and used for the analysis. Descriptive statistics were used for patient demographics, distribution of implants, incidence of biological and prosthetic complications, MBL. Absolute and relative frequency distributions were calculated for qualitative variables, while means, standard deviations (SD), median and confidence interval (CI 95\%) were calculated for quantitative variables. The implant survival was analyzed as a function of time using the Kaplan-Meier method [36], with a patient-based and an implant-based analysis, respectively. In the former, the patient was considered as the statistical unit, whereas in the implant-based analysis each inserted fixture was considered as the statistical unit. In the patient-based analysis, in case of multiple indications for implant therapy (with the same patient receiving more than one implant), the patient was classified as a failure even in the event of a single implant loss. Variables including gender, age at surgery, smoking, bruxism, history of periodontal disease were analyzed at the patient level. Variables including implant location (mandible or maxilla), implant position (incisors, cuspids, premolars, molars), implant length $(8.0,10.0,12.0,14.0 \mathrm{~mm})$, implant diameter $(3.3,4.1,4.8 \mathrm{~mm})$, bone quality type (type I, II, III, IV), site characteristics (grafted or non-grafted sites) were analyzed at the implant level. The quality of bone was identified clinically, at the time of implant placement, during drilling, according to the clinician's judgment [29]. In particular, following the withdrawal of an osteotomy reamer, an assessment of the bone in the reamer flutes was conducted in terms of quality and appearance [29]. Bone quality was classified as type I if the bone was compact, near bloodless cortical bone. Type II bone was red and filled the flutes of the reamer. If no bone remained in the flutes, the bone quality was classified as type IV. If the findings were intermediate between those described for types II and IV, the bone was categorized as type III. In both the patient-based and the implant-based analysis, Log-rank Mantel-Cox, generalized Breslow and Tarone-Ware tests were used to evaluate the outcome of single implants within comparable subgroups. Finally, the Kaplan-Meier method was applied to calculate the cumulative "complication-free" survival rate of implant-supported restorations. All computations were carried out with a statistical software package (SPSS $17.0^{\oplus}$, SPSS Inc.; Chicago, IL, USA). The level of significance was set at 0.05 .

\section{Results}

\section{Patient population and implant-supported restorations}

Over a 12-year period (January 2002- December 2013), 693 patients (348 males, 345 females) were considered for inclusion in this prospective clinical study. With regard to the inclusion/exclusion criteria, 39 patients could not take part in the study $(2$ for severe systemic disease that would not allow a surgical intervention; 9 for active periodontal infections, 2 for benign and/or malignant tumours of the oral cavity, 14 for insufficient bone volume to place implants of at least $3.3 \mathrm{~mm}$ diameter and $8.0 \mathrm{~mm}$ length; 5 for uncontrolled diabetes mellitus, 3 for immunocompromised status, 4 for treatment with oral and/or intravenous aminobisphosphonates). Conversely, 654 patients fulfilled the inclusion criteria, presenting no conditions listed in the exclusion criteria, and were subsequently enrolled in the present study. Among the enrolled patients, aged between 21 and 80 years (mean age 52.7 \pm 14.4 years, median 55, CI 95\% 51.6- 53.8), 324 (49.5\%) were males, while 330 (50.5\%) were females. One-hundred and sixteen patients $(17.7 \%)$ were smokers, 76 patients $(11.6 \%)$ were bruxists, and 228 patients $(34.8 \%)$ had a history of periodontal disease. In total, 762 implants were placed. Three-hundred and seventy-nine implants (49.7\%) were placed in the maxilla, while 383 implants $(50.3 \%)$ were placed in the mandible. With regard to the implant position, $83(10.9 \%)$ were incisors, 73 (9.6\%) were cuspids, 275 (36.1\%) were premolars and 331 (43.4\%) were molars. The most frequently used implant length was $12.0 \mathrm{~mm}(288 \mathrm{implants,} 37.8 \%)$, 
followed by $10.0 \mathrm{~mm}$ (283 implants, 37.2\%), $14.0 \mathrm{~mm}$ (97 implants, 12.7\%) and $8.0 \mathrm{~mm}$ (94 implants, 12.3\%). Despite the implant length, the most frequently used implant diameter was $4.1 \mathrm{~mm}$ (368 implants, $48.3 \%$ ) followed by $4.8 \mathrm{~mm}$ (301 implants, $39.5 \%$ ); $3.3 \mathrm{~mm}$ implants (93 implants, $12.2 \%$ ) were the least used. With regard to the bone quality, 362 implants were placed in type III bone (47.5\%), 202 were placed in type II bone (26.5\%), 159 were placed in type IV bone (20.9\%) and only 39 implants were placed in type I bone (5.1\%). Finally, the vast majority of implants were placed in non-grafted sites (611 implants, $80.1 \%)$ whereas 151 implants were placed in grafted sites (19.9\%).

\section{Implant survival rate}

Of the 654 patients treated from 2002 to 2013, 53 missed the last scheduled appointment control and 4 were lost to follow-up (they missed two or more controls): these patients were classified as drop-outs. At the end of the observation period (December 2014), 597 patients completed the follow-up evaluation in full. The mean follow-up time per patient was $7.5 \pm 3.2$ years. Eighteen implants failed in 18 different patients. The details of the failed implants were reported in Table 1. At the end of this study, an overall 12year cumulative survival rate of $96.9 \%$ (patient-based) and $97.3 \%$ (implant-based) were reported, respectively. In the maxilla, the cumulative survival rate was $96.4 \%$, with 11 failures. In the mandible, the cumulative survival rate was $98.2 \%$, with 7 failures. The evaluation of the influence of different patient-related and implant-related variables on implant survival was reported in Table 2 and in Table 3, respectively. The survival rate did not differ significantly with respect to patients' gender, age, smoking, bruxism, history of periodontal disease, implant location, position, length, diameter, bone and site ( $\mathrm{p}>0.05)$. The majority of implants (14) were lost within the healing period, before the connection of the prosthetic abutment: accordingly, these fixtures were classified as "early failures", due to lack of osseointegration/implant mobility without any clinical sign of infection (10 implants), or recurrent/ persistent peri-implantitis ( 4 implants) with pain and suppuration, before functional loading. Conversely, 4 implants failed after the abutment connection, and were classified as "late failures". These fixtures failed respectively 9, 8, 4 and 3 years after placement. The first two implants failed because of progressive bone loss in absence of signs of peri-implant infections; the other two implants failed because of severe bone loss due to recurrent/persistent peri-implant infections, with pain, suppuration/exudation and fistula formation.

\begin{tabular}{|c|c|c|c|c|c|c|c|}
\hline & Time (month) & Reason & Location & Position & Bone quality & Grafted site & Total \\
\hline \multirow{14}{*}{$\begin{array}{l}\text { Early } \\
\text { failures }\end{array}$} & 3 & LO & mandible & cuspid & II & no & \multirow{14}{*}{14} \\
\hline & 3 & LO & mandible & incisor & I & yes & \\
\hline & 3 & LO & mandible & premolar & III & yes & \\
\hline & 3 & PI & mandible & molar & IV & yes & \\
\hline & 4 & LO & mandible & molar & IV & no & \\
\hline & 4 & LO & maxilla & molar & III & no & \\
\hline & 4 & PI & maxilla & premolar & III & no & \\
\hline & 3 & LO & maxilla & molar & III & no & \\
\hline & 4 & LO & maxilla & premolar & IV & no & \\
\hline & 4 & LO & maxilla & molar & IV & no & \\
\hline & 4 & LO & maxilla & molar & IV & yes & \\
\hline & 4 & PI & mandible & premolar & II & yes & \\
\hline & 4 & LO & maxilla & molar & IV & no & \\
\hline & 3 & PI & mandible & premolar & III & no & \\
\hline \multirow{4}{*}{$\begin{array}{c}\text { Late } \\
\text { failures }\end{array}$} & 96 & MO & maxilla & molar & IV & no & \multirow{4}{*}{4} \\
\hline & 108 & MO & maxilla & molar & IV & yes & \\
\hline & 48 & PI & maxilla & molar & III & no & \\
\hline & 36 & PI & maxilla & premolar & III & no & \\
\hline
\end{tabular}

$\mathrm{LO}=$ lack of osseointegration in absence of any sign of peri-implant infection; PI = peri-implantitis; $\mathrm{MO}=$ progressive bone loss due to mechanical overload Table 1: Details of failures

\section{Complications}

Among the surviving 744 implants, over a period of 12 years, 45 (45/744: 6.0\%) suffered from biological complications, while 26 (26/744: 3.4\%) suffered from prosthetic complications, for an overall cumulative "complication-free" survival of restorations of $72.7 \%$. At the end of the study, the cumulative survival rate of restorations free of any biological complication was $79.7 \%$, while the cumulative survival rate of restorations free of any prosthetic complications was $91.5 \%$. All complications encountered during the observation period were summarized in Table 4. 


\begin{tabular}{|c|c|c|c|c|c|c|}
\hline & $\mathbf{N}^{\circ}$ & Failures & Kaplan-Meier & $\begin{array}{c}\text { Log-rank } \\
\text { (Mantel-Cox) }\end{array}$ & $\begin{array}{c}\text { Breslow } \\
\text { (generalized } \\
\text { Wilcoxon) }\end{array}$ & Tarone-Ware \\
\hline All patients & 654 & 18 & 96.9 & - & - & - \\
\hline \multicolumn{7}{|c|}{ Gender } \\
\hline Males & 324 & 8 & 97.2 & \multirow{2}{*}{.624} & \multirow{2}{*}{.616} & \multirow{2}{*}{.616} \\
\hline Females & 330 & 10 & 96.6 & & & \\
\hline \multicolumn{7}{|c|}{ Age } \\
\hline $21-40$ years & 124 & 4 & 96.7 & \multirow{3}{*}{.957} & \multirow{3}{*}{.859} & \multirow{3}{*}{.905} \\
\hline 41-60 years & 336 & 8 & 97.0 & & & \\
\hline $61-80$ years & 194 & 6 & 96.9 & & & \\
\hline \multicolumn{7}{|c|}{ Smoking } \\
\hline Yes & 116 & 6 & 93.5 & \multirow{2}{*}{.089} & \multirow{2}{*}{.209} & \multirow{2}{*}{.146} \\
\hline No & 538 & 12 & 97.7 & & & \\
\hline \multicolumn{7}{|c|}{ Bruxism } \\
\hline Yes & 76 & 4 & 94.0 & \multirow{2}{*}{.172} & \multirow{2}{*}{.242} & \multirow{2}{*}{.206} \\
\hline No & 578 & 14 & 97.3 & & & \\
\hline \multicolumn{7}{|c|}{ History of periodontal disease } \\
\hline Yes & 228 & 8 & 95.6 & \multirow{2}{*}{.377} & \multirow{2}{*}{.537} & \multirow{2}{*}{.466} \\
\hline No & 426 & 10 & 97.6 & & & \\
\hline
\end{tabular}

Table 2: Details of implant survival (patient-based analysis)

\begin{tabular}{|c|c|c|c|c|c|c|}
\hline & $\mathbf{N}^{\circ}$ & Failures & Kaplan-Meier & $\begin{array}{c}\text { Log-rank } \\
\text { (Mantel-Cox) }\end{array}$ & $\begin{array}{c}\text { Breslow } \\
\text { (generalized } \\
\text { Wilcoxon) }\end{array}$ & Tarone-Ware \\
\hline Overall & 762 & 18 & 97.3 & - & - & - \\
\hline \multicolumn{7}{|c|}{ Implant location } \\
\hline Maxilla & 379 & 11 & 96.4 & \multirow{2}{*}{.325} & \multirow{2}{*}{.486} & \multirow{2}{*}{.409} \\
\hline Mandible & 383 & 7 & 98.2 & & & \\
\hline \multicolumn{7}{|c|}{ Implant position } \\
\hline Incisor & 83 & 1 & 98.8 & \multirow{4}{*}{.736} & \multirow{4}{*}{.833} & \multirow{4}{*}{.793} \\
\hline Cuspid & 73 & 1 & 98.6 & & & \\
\hline Premolar & 275 & 6 & 97.8 & & & \\
\hline Molar & 331 & 10 & 96.4 & & & \\
\hline \multicolumn{7}{|c|}{ Implant length } \\
\hline $8.0 \mathrm{~mm}$ & 94 & 3 & 96.2 & \multirow{4}{*}{.814} & \multirow{4}{*}{.849} & \multirow{4}{*}{.838} \\
\hline $10.0 \mathrm{~mm}$ & 283 & 7 & 97.5 & & & \\
\hline $12.0 \mathrm{~mm}$ & 288 & 7 & 97.0 & & & \\
\hline $14.0 \mathrm{~mm}$ & 97 & 1 & 99.0 & & & \\
\hline \multicolumn{7}{|c|}{ Implant diameter } \\
\hline $3.3 \mathrm{~mm}$ & 93 & 2 & 97.8 & \multirow{3}{*}{.984} & \multirow{3}{*}{.986} & \multirow{3}{*}{.986} \\
\hline $4.1 \mathrm{~mm}$ & 368 & 9 & 97.2 & & & \\
\hline $4.8 \mathrm{~mm}$ & 301 & 7 & 97.3 & & & \\
\hline \multicolumn{7}{|c|}{ Bone type } \\
\hline I & 39 & 1 & 97.4 & \multirow{4}{*}{.090} & \multirow{4}{*}{.162} & \multirow{4}{*}{.126} \\
\hline II & 202 & 2 & 99.0 & & & \\
\hline III & 362 & 7 & 98.0 & & & \\
\hline IV & 159 & 8 & 94.0 & & & \\
\hline \multicolumn{7}{|c|}{ Site type } \\
\hline Grafted & 151 & 6 & 95.4 & \multirow{2}{*}{.152} & \multirow{2}{*}{.177} & \multirow{2}{*}{.167} \\
\hline Non-grafted & 611 & 12 & 97.8 & & & \\
\hline
\end{tabular}

Table 3: Details of implant survival (implant-based analysis) 


\begin{tabular}{|c|c|c|}
\hline & $\mathbf{N}^{\circ}$ of complications & $\%$ \\
\hline \multicolumn{2}{|c|}{ Biological complications } \\
\hline Pain/swelling after surgery & $9 / 744$ & $1.2 \%$ \\
\hline Peri-implant mucositis & $16 / 744$ & $2.1 \%$ \\
\hline Peri-implantitis & $10 / 744$ & $1.3 \%$ \\
\hline $\begin{array}{c}\text { Progressive marginal bone loss in absence of } \\
\text { clinical signs of infection }\end{array}$ & $10 / 744$ & $1.3 \%$ \\
\hline Overall biological & $45 / 744$ & $6.0 \%$ \\
\hline Prosthetic complications & \\
\hline Decementation & $13 / 744$ & $1.7 \%$ \\
\hline Ceramic chipping/fracture & $10 / 744$ & $1.3 \%$ \\
\hline Abutment loosening & $3 / 744$ & $0.4 \%$ \\
\hline Abutment fractures & $0 / 744$ & $0.0 \%$ \\
\hline Overall prosthetic & $26 / 744$ & $3.4 \%$ \\
\hline
\end{tabular}

Table 4: Details of complications

\section{Marginal bone loss (MBL)}

The radiographic evaluation of the implants revealed a mean MBL of $0.34 \pm 0.27 \mathrm{~mm}$ (median, $0.4 \mathrm{~mm} ; 95 \% \mathrm{CI}=0.33$ to 0.35 $\mathrm{mm}$ ), $0.46 \pm 0.29 \mathrm{~mm}$ (median, $0.4 \mathrm{~mm} ; 95 \% \mathrm{CI}=0.44$ to $0.48 \mathrm{~mm}$ ) and $0.83 \pm 0.41 \mathrm{~mm}$ (median, $0.7 \mathrm{~mm} ; 95 \% \mathrm{CI}=0.75$ to 0.91 $\mathrm{mm}$ ), at the 1-, 6- and 12-year follow-up sessions, respectively (Figures 2).
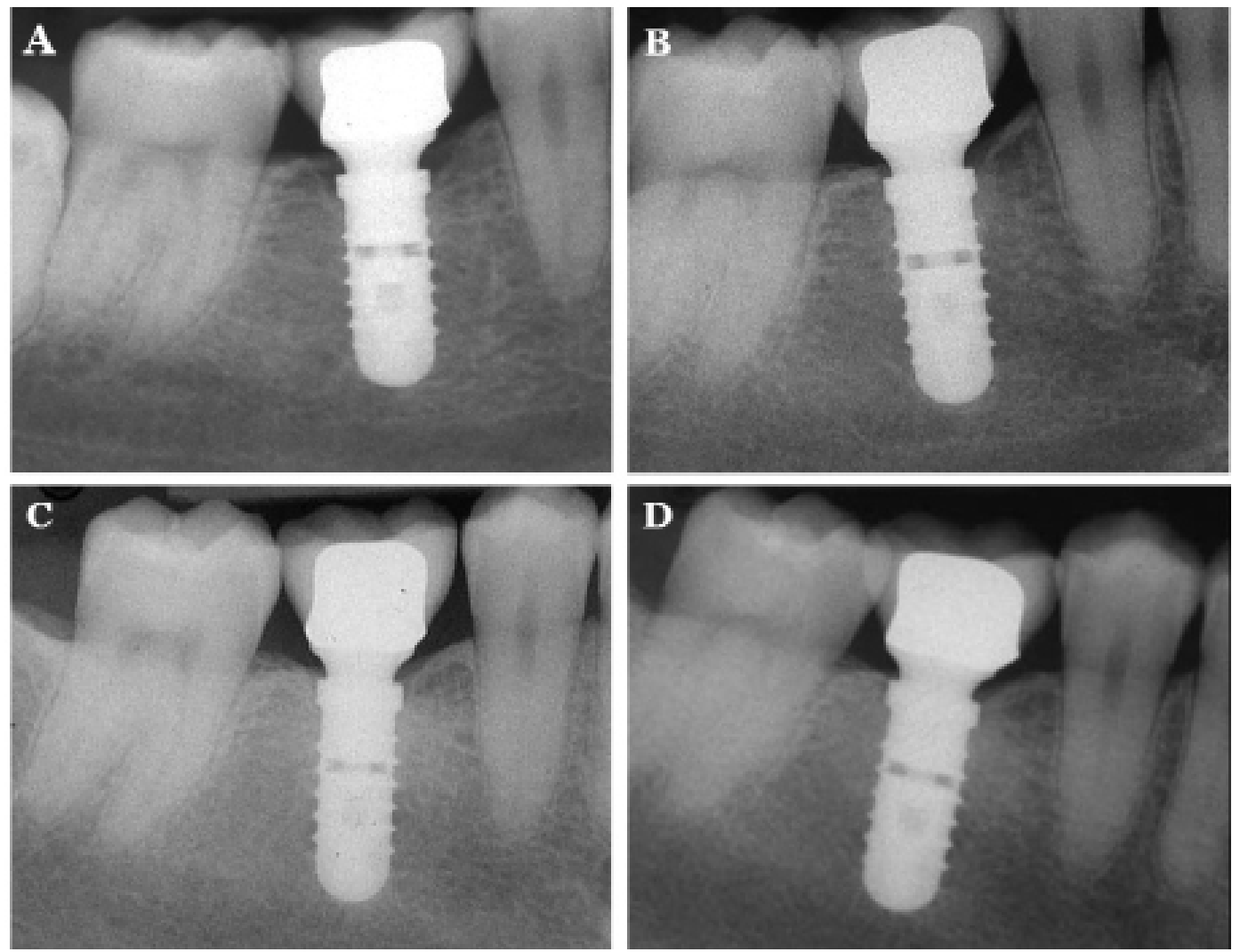

Figure 2: Peri-apical radiographs of a mandibular first molar. Rx taken at placement of the definitive restoration (A) 1 year after placement (B) 6 years after placement (C) 12 years after placement

\section{Discussion}

Despite the high survival rates and predictability of rehabilitating patients with single- tooth restorations using dental implants, prosthetic complications (abutment screw loosening/fracture, chipping/fracture of veneering materials, need for recementation) still remain an issue; managing these complications can cause extra amount of chair-side time, additional costs and patient dissatisfaction $[2,5-10]$. 
Abutment screw loosening was described already in 1996 as the most common complication affecting abutments tightened with a titanium screw [15]. The reasons for screw loosening are fatigue, inadequate tightening torque, settling effect, vibrating micromovements and excessive bending [19-22]. It must be emphasized that in the first studies, old gold-screw design was mainly responsible for the high number of screw- loosening [13,15]; in the late 2000s, after the improvements of the abutment screw materials and the recommendation of system-specific torque values, a reduction in the incidence of abutment screw loosening was reported, at least in short-term studies [12].

When cemented restorations were developed and prosthetic retaining screws were replaced by luting cement, the incidence of screw loosening was further reduced [12,37]. However, despite the progresses produced by these improvements in the shortterm, recent long-term clinical studies have reported an increasing prosthetic complication occurrence with time, confirming that abutment screw loosening continues to be an important issue for clinicians $[2,7,8,10]$. In a long-term retrospective study evaluating the survival rates and the frequency of complications associated with implant-supported SCs [2], excellent implant survival rates were found, with a high frequency of complications (29.6\%). The frequency of biological complications was $4.3 \%$, whereas prosthetic complications occurred in $22.5 \%$ of cases [2]. The predominant complication involved loose abutment screws, which occurred in $21.1 \%$ of restorations [2]. In a retrospective study investigating the survival and complication rates of single implants in periodontally healthy patients after 16-22 years of follow-up, Dierens and colleagues found encouraging prosthetic survival rates [7]. However, $66 \%$ of the patients encountered at least one complication during follow-up, so that only $39 \%$ of implants remained complication- free throughout the mean 18.5 years [7]. In particular, prosthetic complications were most common, with a high incidence of abutment screw loosening (26\%), veneer chipping or fracture (7\%), and loss of retention (3\%) [7]. Nevertheless, no abutment or abutment screw fractures were reported [7]. In another recent 10-year retrospective study [8], the rate of mechanical/technical complications and failures of 397 fixed implant-supported fixed restorations, including 268 single crowns, was assessed. At the end of the study, the most frequent prosthetic complication was ceramic chipping (20.3\%) followed by occlusal screw loosening (2.5\%) and loss of retention (2.0\%) [8] One abutment loosening and two abutment fractures were reported. This resulted in a total mechanical/technical complication rate of $24.7 \%$, with a prosthetic success rate over a mean follow-up time of 10.75 years was $70.8 \%$ [8]. Previous studies had described $66 \%$ complication-free crown maintenance after 10 years [6]. An high incidence of prosthetic complication was also reported in a retrospective study on 65 patients receiving 112 single-tooth molar restorations [10]. In this study, 30 technical complications were observed (16 loss of retention, 10 ceramic fractures, 4 screw loosening), for a success rate of superstructures of $79 \%$ after 7 years [10]. Overall, 9.2\% of the patients developed peri-implantitis [10].

In a recent systematic review on implant-supported SCs [12], the authors reported an implant survival rate of $96.3 \%$ after 5 years. For biological complications, a 5-year cumulative soft tissue complication rate of $7.1 \%$ and a cumulative complication rate for implants with bone loss $>2 \mathrm{~mm}$ of $5.2 \%$ were calculated [12]. Prosthetic complications reached a cumulative incidence of $8.8 \%$ for screw-loosening, $4.1 \%$ for loss of retention, and 3.5\% for fracture of the veneering material after 5 years [12]. In another similar review, the authors found an overall 5-year rate for technical complications of $11.8 \%$, whereas biological complications occurred with an overall rate of $6.4 \%$ [13].

In our present study, only 18 of 762 implants failed, giving a satisfactory high cumulative implant survival of $96.9 \%$ (patientbased) and $97.3 \%$ (implant-based) at 12-year follow-up, respectively. The lower survival rate was reported for smokers (93.5\%), in accordance with the current literature [33], although no statistically significant differences were found in the survival rates of smoking and non-smoking patients. Most notably, a 12-year cumulative "complication-free" survival of restorations of $72.7 \%$ was reported. In fact, only three prosthetic abutments (0.4\%), located in the posterior mandible, became loose over a period of 12 years. No other mechanical complications occurred. The most frequent prosthetic complications were technical in nature, with 13 decementation (1.7\%) and 10 chipping/fracture of the veneer material (1.3\%) occurred. Overall, the incidence of prosthetic complication was very low (3.4\%). The implant-abutment connection system used in this study is a locking-taper connection guided by an internal hexagon. This connection presents a taper angle of 1.5 degrees, and it is able to induce a self-locking mating between the parts; this implant-abutment connection seems to be able to reduce the incidence of mechanical complications affecting single-tooth restorations, as reported in previous studies [24,25,27-31]. It should be emphasized that in our study the majority of the implants were placed in the posterior areas of jaws, where the mechanical loads are higher, with greater risk of prosthetic complications.

After implant placement, re-establishment of biologic width results in a certain amount of bone loss [38]. A recent study has evidenced that apical implant positioning may result in early peri-implant bone resorption [39]. In screw-type implant systems, a microgap of variable dimensions (40 to 100 micro-meters) can be found at the implant-abutment interface [40,41]. This gap can be colonized by bacteria [40,41], which generate a chemotactic stimulus, recruiting inflammatory cells $[42,43]$. This finally results in the development of inflammatory reactions in the peri-implant soft tissues and bone loss [42,43]. Some authors have advocated that a higher bacterial contamination may be related to a misfit at the implant-abutment interface, caused by screw loosening $[42,43]$. Locking-taper implants may provide an efficient seal against microbial penetration, reducing the microgap (1 to 3 micrometers) dimensions at the implant-abutment interface, and contributing to a minimal level of peri-implant tissue inflammation $[44,45]$. 
In our present long-term follow-up study, a low incidence of biological complications (6.0\%) was reported, and stable bone levels were observed around these implants over time, with a mean MBL of $0.34( \pm 0.27 \mathrm{~mm}), 0.46( \pm 0.29 \mathrm{~mm})$ and $0.83( \pm 0.41 \mathrm{~mm})$ at the 1-, 6- and 12-year follow-up examinations, respectively. Although MBL is a commonly used index in clinical trials, it has limitations: in fact, it is based on two-dimensional (2D) measurements made on peri-apical radiographs, and therefore it can be affected by distortions. In our present study, however, the implant dimension (length) was measured on the radiograph and then compared with the actual fixture dimensions: ratios were calculated to adjust for distortion. In addition, all radiographs were taken with the same technique, and customized positioners, composed of polyvinyl siloxane, were used for precise repositioning and stabilization of the radiographic template.

Locking-taper implants incorporate the "platform switching" design concept, and its distinct advantages [24,25,27-31]. The biologic rationale of the platform-switching design or horizontal set-off at the implant-abutment interface is actually explained as the consequence of the horizontal repositioning of the microgap [46-48]. Basically, the principle involved is to distance the implant-abutment microgap away from the bone as far as possible. This is useful, because the microgap harbors bacteria that produce toxins; if bacteria are more distant from the bone, it is subsequently possible to minimize bone loss [46-48]. Another consequence of platform-switching design is the increased space for more connective tissue, to improve the biologic seal: this space can guarantee excellent soft-tissue healing, with a thicker and larger well-organized amount of peri-implant soft tissues, protecting the bone crest from resorption [48].

These findings were confirmed in a recent randomized controlled split-mouth trial, where the use of implants with conical connection and a built-in platform resulted in less crestal bone loss and excellent bone stability over time compared to fixtures with a flat-to-flat external hexagonal connection with abutments of matching diameter [49].

\section{Conclusions}

Based on this study, it can be concluded that locking-taper implants represent a valid and predictable treatment modality for single tooth replacement in the long term, even in the posterior areas of both arches. In fact, locking-taper implants showed a satisfactory high cumulative survival rate of $96.9 \%$ (patient-based) and $97.3 \%$ (implant-based) at 12-year follow-up. A low incidence of biological (6.0\%) and prosthetic (3.4\%) complications was reported, with only three loosened abutments in the posterior regions of the mandible, giving a 12-year cumulative "complication-free" survival of restorations of $72.7 \%$. Finally, stable bone levels were observed around these implants, with a mean MBL of $0.34( \pm 0.27 \mathrm{~mm}), 0.46( \pm 0.29 \mathrm{~mm})$ and $0.83( \pm 0.41 \mathrm{~mm})$ at the 1-, 6- and 12-year follow-up examinations, respectively.

\section{Acknowledgment}

No conflict of interests are reported for the present clinical investigation.

\section{References}

1. Dierens M, Vandeweghe S, Kisch J, Nilner K, De Bruyn H (2012) Long-term follow-up of turned single implants placed in periodontally healthy patients after 16-22 years: radiographic and peri-implant outcome. Clin Oral Implants Res 23: 197-204.

2. Camargos GDe V, do Prado CJ, das Neves FD, Sartori IA (2012) Clinical outcomes of single dental implants with external connections: results after 2 to 13 years. Int J Oral Maxillofac Implants 27: 935-44.

3. Sesma N, Pannuti C, Cardaropoli G (2012) Retrospective clinical study of 988 dual acid-etched implants placed in grafted and native bone for single-tooth replacement. Int J Oral Maxillofac Implants 27: 1243-8.

4. Mozzati M, Gallesio G, Del Fabbro M (2015) Long-term (9-12 years) outcomes of titanium implants with an oxidized surface: a retrospective investigation on 209 implants. J Oral Implantol 41: 437-43.

5. Pjetursson BE, Asgeirsson AG, Zwahlen M, Sailer I (2014) Improvements in implantdentistry over the last decade: comparison of survival and complication rates in older and newer publications. Int J Oral Maxillofac Implants 29: 308-24.

6. Bragger U, Karoussis I, Persson R, Pjetursson B, Salvi G, et al. (2005) Technical and biological complications/failures with single crowns and fixed partial dentures on implants: a 10-year prospective cohort study. Clin Oral Implants Res 16: 326-34.

7. Dierens M, De Bruyn H, Kisch J, Nilner K, Cosyn J, et al. (2014) Prosthetic Survival and Complication Rate of Single Implant Treatment in the Periodontally Healthy Patient after 16 to 22 Years of Follow-Up. Clin Implant Dent Rel Res Sep 5. doi:10.1111/cid.12266.

8. Wittneben JG, Buser D, Salvi GE, Burgin W, Hicklin S, et al. (2014) Complication and failure rates with implant-supported fixed dental prostheses and single crowns: a 10- year retrospective study. Clin Implant Dent Relat Res 16: 356-64.

9. Walton TR (2015) An Up-to-15-Year Comparison of the Survival and Complication Burden of Three-Unit Tooth-Supported Fixed Dental Prostheses and Implant-Supported Single Crowns. Int J Oral Maxillofac Implants 30: 851-61.

10. Rinke S, Roediger M, Eickholz P, Lange K, Ziebolz D (2015) Technical and biological complications of single-molar implant restorations. Clin Oral Implants Res 26: 1024-30.

11. Salvi GE, Bragger U (2009) Mechanical and technical risks in implant therapy. Int J Oral Maxillofac Implants 24: 69-85.

12. Jung RE, Zembic A, Pjetursson BE, Zwahlen M, Thoma DS (2012) Systematic reviewof the survival rate and the incidence of biological, technical, and aesthetic complications of single crowns on implants reported in longitudinal studies with a mean follow-up of 5 years. Clin Oral Implants Res 23: 2-21.

13. Zembic A, Kim S, Zwahlen M, Kelly JR (2014) Systematic review of the survival rateand incidence of biologic, technical, and esthetic complications of single implant abutments supporting fixed prostheses. Int J Oral Maxillofac Implants 29: 99-116. 
14. Ekfeldt A, Carlsson GE, Borjesson G (1994) Clinical evaluations of single-tooth restorations supported by osseointegrated implants: A retrospective study. Int J Oral Maxillofac Implants 9: 179-83.

15. Henry PJ, Laney WR, Jemt T, Harris D, Krog PH, et al. (1996) Osseointegrated implants for single-tooth replacement: a prospective 5-year multicenter study. Int J Oral Maxillofac Implants 11: 450-5.

16. Wannfors K, Smedberg JI (1999) A prospective clinical evaluation of different single- tooth restoration designs on osseointegrated implants. Clin Oral Implants Res 10: 453-8.

17. Schwarz MS (2000) Mechanical complications of dental implants. Clin Oral Implants Res 11: 156-8.

18. Gracis S, Michalakis K, Vigolo P, Vult von Steyern P, Zwahlen M, et al. (2012) Internal vs. external connections for abutments/reconstructions: a systematic review. Clin Oral Implants Res 23: 202-16.

19. Kim ES, Shin SY (2013) Influence of the implant abutment types and the dynamic loading on initial screw loosening. J Adv Prosthodont 5: 21-8.

20. Michalakis K, Calvani P, Muftu S, Pissiotis A, Hirayama H (2014) The effect of different implant-abutment connections on screw joint stability. J Oral Implantol 40: 146-52.

21. Schmitt CM, Nogueira-Filho G, Tenenbaum HC, Lai JY, Brito C, et al. (2014) Performance of conical abutment (Morse Taper) connection implants: a systematic review. J Biomed Mater Res A 102: 552-74.

22. Bozkaya D, Muftu S (2003) Mechanics of the tapered interference fit in dental implants. J Biomech 36: 1649-58.

23. Sannino G, Barlattani A (2013) Mechanical evaluation of an implant-abutment self- locking taper connection: finite element analysis and experimental tests. Int J Oral Maxillofac Implants 28: e17-26.

24. Mangano C, Mangano F, Piattelli A, Iezzi G, Mangano A, et al. (2010) Prospective clinical evaluation of 307 single-tooth morse taper-connection implants: a multicenter study. Int J Oral Maxillofac Implants 25: 394-400.

25. Urdaneta RA, Daher S, Lery J, Emanuel K, Chuang SK (2011) Factors associated with crestal bone gain on single-tooth locking-taper implants: the effect of nonsteroidal anti- inflammatory drugs. Int J Oral Maxillofac Implants 26: 1063-78.

26. Urdaneta RA, Marincola M, Weed M, Chuang SK (2008) A screwless and cementless technique for the restoration of single-tooth implants: a retrospective cohort study. J Prosthodont 17: 562-71

27. Urdaneta RA, Daher S, Leary J, Emanuel KM, Chuang SK (2012) The survival of ultrashort locking-taper implants. Int J Oral Maxillofac Implants 27: 644-54. 28. Mangano F, Macchi A, Caprioglio A, Sammons RL, Piattelli A, et al. (2014) Survival and complication rates of fixed restorations supported by locking-taper implants: a prospective study with 1 to 10 years of follow-up. J Prosthodont 23: 434-44.

29. Mangano FG, Shibli JA, Sammons RL, Iaculli F, Piattelli A, et al. (2014) Short(8-mm) locking-taper implants supporting single crowns in posterior region: a prospective clinical study with 1-to 10-years of follow-up. Clin Oral Implants Res 25: 933-40.

30. Mangano F, Shibli JA, Sammons RL, Veronesi G, Piattelli A, et al. (2014) Clinical outcome of narrow-diameter (3.3-mm) locking-taper implants: a prospective study with 1 to 10 years of follow-up. Int J Oral Maxillofac Implants 29: 448-55.

31. Mangano C, Iaculli F, Piattelli A, Mangano F (2015) Fixed restorations supported by Morse-taper connection implants: a retrospective clinical study with 10-20 years of follow- up. Clin Oral Implants Res 26: 1229-36.

32. Kreissl ME, Gerds T, Muche R, Heydecke G, Strub JR (2007) Technical complications of implant-supported fixed partial dentures in partially edentulous cases after an average observation period of 5 years. Clin Oral Implants Res 18: 720-6.

33. Chambrone L, Preshaw PM, Ferreira JD, Rodrigues JA, Cassoni A, et al. (2014) Effects of tobacco smoking on the survival rate of dental implants placed in areas of maxillary sinus floor augmentation: a systematic review. Clin Oral Implants Res 25: 408-16.

34. American Academy of Periodontology (2013) Peri-implant mucositis and peri- implantitis: A current understanding of their diagnoses and clinical implications. J Periodontol 84: 436-43.

35. Albrektsson T, Isidor F (1994) Consensus report of session IV. In Lang NP, Karring T, eds. Proceedings of the 1st European Workshop on Periodontology Quintessence Publishing Co Ltd 365-9.

36. Kaplan EL, Meier P (1958) Non-parametric estimation from incomplete observation. J Am Stat Ass 53: 457-81.

37. Theoharidou A, Petridis HP, Tzannas K, Garefis P (2008) Abutment screw loosening in single-implant restorations: a systematic review. Int J Oral Maxillofac Implants 23: 681-90.

38. Oh TJ, Yoon J, Misch CE, Wang HL (2002) The causes of early implant bone loss: Myth or science? J Periodontol 73: $322-33$.

39. Hof M, Pommer B, Zukic N, Vasak C, Lorenzoni M, et al. (2015) Influence of prosthetic parameters on peri-implant bone resorption in the first year of loading: a multi- factorial analysis. Clin Implant Dent Rel Res 17: e138-91.

40. Weng D, Nagata MJ, Bell M, Bosco AF, de Melo LG, et al. (2008) Influence of microgap location and configuration on the periimplant bone morphology in submerged implants. An experimental study in dogs. Clin Oral Implants Res 19: 1141-7.

41. Todescam FF, Pustiglioni FE, Imbronito AV, Albrektsson T, Gioso M (2002) Influence of the microgap in the periimplant hard and soft tissues: A histomorphometric study in dogs. Int J Oral Maxillofac Implants 17: 467-72.

42. Piattelli A, Vrespa G, Petrone G, Iezzi G, Annibali S, et al. (2003) Role of the microgap between implant and abutment: A retrospective histologic evaluation in monkeys. J Periodontol 74: 346-52.

43. Broggini N, McManus LM, Hermann JS, Medina RU, Oates TW, et al. (2003) Persistent acute inflammation at the implant-abutment interface. J Dent Res 82: 232-7.

44. Dibart S, Warbington M, Su MF, Skobe Z (2005) In vitro evaluation of the implant- abutment bacterial seal: The locking taper system. Int J Oral Maxillofac Implants 20: 732-7.

45. Pappalardo S, Milazzo I, Nicoletti G, Baglio O, Blandino G, et al. (2007) Dental implants with locking taper connection versus screwed connection: microbiologic and scanning electron microscope study. Int J Immuno Pharm 20: 13-7.

46. Chrcanovic BR, Albrektsson T, Wennerberg A (2015) Platform switch and dental implants: A meta-analysis. J Dent $43: 629-46$.

47. Monje A, Pommer B (2015) The Concept of Platform Switching to Preserve Peri- implant Bone Level: Assessment of Methodologic Quality of Systematic Reviews. Int J Oral Maxillofac Implants 30: 1084-92. 
48. Al-Nsour MM, Chan HL, Wang HL (2012) Effect of the platform-switching technique on preservation of peri-implant marginal bone: a systematic review. Int J Oral Maxillofac Implants 27: 138-45.

49. Pozzi A, Agliardi E, Tallarico M, Barlattani A (2014) Clinical and radiological outcomes of two implants with different prosthetic interfaces and neck configurations: randomized, controlled, split-mouth clinical trial. Clin Implant Dent Relat Res 16: 96-106.

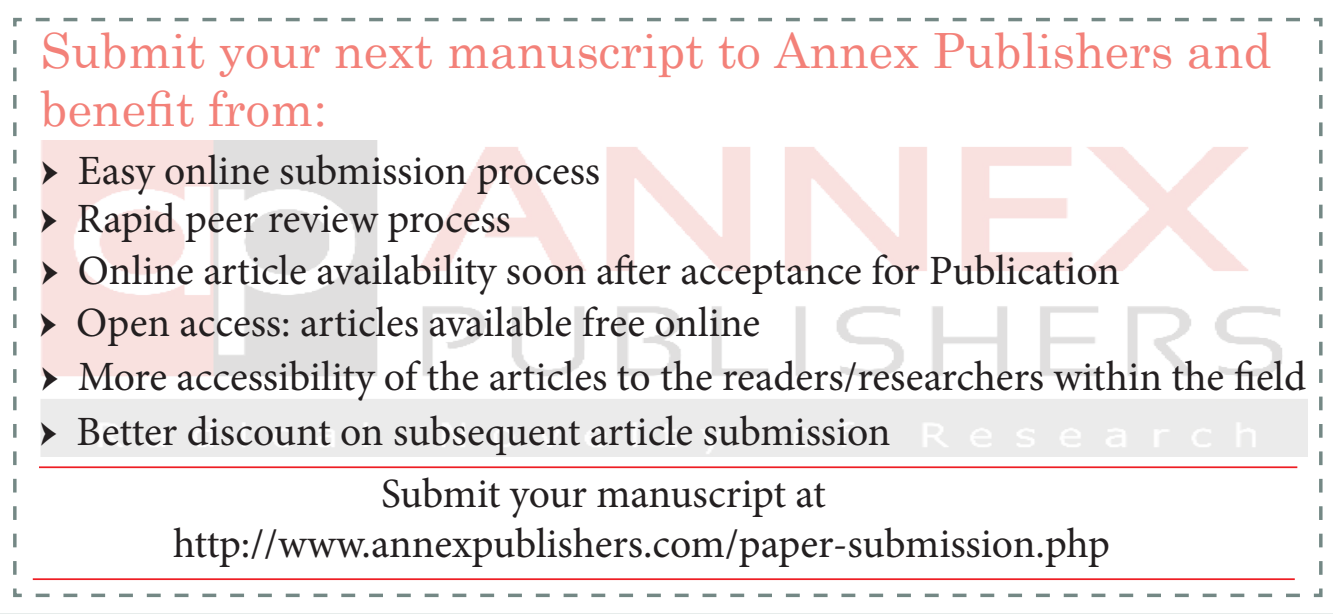


